\title{
Standards of Advertisements: Misleading Effects Vs Subliminal Understanding
}

\author{
K.Prabhakar Rajkumar, M.Priya
}

\begin{abstract}
An introduction of the investigation on the common advertisement. Marketing is a type of communication meant to urge viewers to buy or even take some action upon products, tips, or even solutions. Advertising and marketing is actually the key to market and broadcast products and brands. Today the degrading criteria of marketing are actually straight impacting the much younger viewers generating a bad influence on the little ones. The advertisers aren't being able to segregate the time ports as well as decide concerning that is their target audience. Advertising ought to not simply concern producing Income but likewise concerning generating it coming from the right target market and also not through developing an overwhelming impact on people who shouldn't be actually influenced or are actually not the target audience of the item. In every genre of the media, newspaper, broadcast, television, the regulations for conventional advertising and marketing must be formulated.
\end{abstract}

Keywords: Standard, Advertising, Communication, Services.

\section{INTRODUCTION}

An ad is actually an advertising and marketing tool which is actually used offer for sale promotion and also publicity. It is actually a paid for kind of non-personal discussion and also advertising of suggestions, goods or even solutions through an identified supporter. Advertising and marketing methods are actually utilized to make the items, services or point of views acquainted to individuals. It is a process of interaction in between the owner of the services or products as well as individuals. The buyers end up being acquainted to the effectiveness as well as energy of the existing products and potential products. It aids the consumer in taking ideal selection as well as it is a craft as well as communication method where the Hallmark or brand of the product and services is created understood to individuals. According to William J. Stanton, "Advertising contains all the activities associates with showing to a group, a non-personal, dental or aesthetic, honestly funded message regarding disseminated by means of one or more media as well as is purchased through an identified sponsor".

The principal object of advertising is to offer an item, a service or an idea. It executes an efficient communication in between producers as well as prospective or even current

buyers. Nonetheless, following are actually several of the goals of advertising and marketing:

$>$ It helps a new item to be identified in the market;

$>$ It helps to raise sale and also demand of the products;

It aids to create a label photo as well as devotion on the market;

$>$ It develops a goodwill of the item;

Revised Manuscript Received on November 05, 2019.

Dr. K.Prabhakar Rajkumar, Associate Professor, Department of Commerce, Periyar University, Salem -11, Tamil Nadu, India.

M.Priya, PH.D Research Scholar, Periyar University, Salem -11, Tamil Nadu, India.Email : kudalkprk6@yahoo.co.in. $>\quad$ It notifies the consumers the important adjustments with regard to costs, top qualities and also packaging of the items.

\section{FALSE ADVERTISING}

False Advertising and marketing is actually making use of incorrect, confusing, or unproven details to advertise items to consumers. The advertising and marketing regularly carries out not divulge its resource. One form of inaccurate advertising is actually to state that a product possesses a wellness perk or even contains vitamins or even minerals that it as a matter of fact carries out certainly not. Lots of authorities utilize rules to manage false marketing. An untrue ad can easily even more be actually identified as misleading if the marketer intentionally deceives the consumer, instead of creating a sincere blunder.

In PepsiCo Inc. And ors. Vs. Hindustan Coca Cola Ltd. And also Anr., It was kept by the Hon' ble Delhi High Court thatcomparison advertising is actually acceptable based on the biker that it Carries out certainly not denigrate the item of the applicant. If an investor compares his products with the goods Of competitor without in any way marketing that the trade score is made use of in relation to his goods, there is prima facie no infringement.

In Dabur India Ltd. Vs. Colgate Palmolive India Ltd., Hon' ble Delhi High Court kept that. "generic disparagement of a competing item without specifically recognizing or determining the Competing item is just as objectionable. Cleaver advertising and marketing can easily undoubtedly strike a rivalrous product without Specifically pertaining to it.No one may disparage a lesson or even genre of a product within which a Whining plaintiff drops as well as elevate a protection that the injured party has not been particularly Identified. "

In Dabur India Limited vs Emami Limited: Hon' ble Delhi High Court held that a.

Supplier is actually qualified to help make a declaration that his products are actually the very best as well as also help make some statements for puffing of his items but the exact same would certainly not provide a root cause of action to various other traders a cause of action to various other investors or producers of comparable items to set up go ahead traders There is no disparagement or even libel to the goods of the supplier thus carrying out. However, a Supplier is certainly not entitled to claim that his competition's goods are bad therefore in order to puff as well as advertise his goods. In Karamchand Appliances Pvt. Ltd. Vs. Adhikary Brothers \& Ors: Hon' ble Delhi High Court held that a supplier or a tradesperson is allowed to possess that his items are the most effective around the world, 
even if such an insurance claim is factually wrong, as well as while a case that the goods of a Producer or the tradesperson are actually the very best might certainly not supply a reason for action to every other trader Or supplier of comparable items, the second the rival maker or even investor slanders or even Slanders the goods of an additional producer or even trader, the aggrieved trader would certainly be actually qualified also Seek alleviates featuring requital using a propitiatory ruling. The defendant is without a doubt entitled to exhibit that its item is the most recent in the market and even the very best but it can easily not explain either the technology or even the idea utilized through every other supplier Or even trader in the manufacture or even purchase of his items as outdated or meaningless. Comparison Promotion is permitted, such a long time because of this contrast performs certainly not slander or denigrate the Hallmark or the items of a competition. Comparison of different functions of pair of products Showing the perks, which one product enjoy over the other is likewise permitted given Such comparison stops short of discrediting or even derogating the other product.".

In Surprise Forbes Ltd., Kolkata and its neighborhood workplace at Bangalore Vs Pentair Water India Pvt. Ltd., Goa, Hon' ble Karnataka High Court at Bangalore, stored that ..." an advertiser can easily state That his items are better than his competitions yet he can easily not mention that his rivals products are Bad since that would certainly amount to tarnishing or even slandering competition and also its own goods, which is Certainly not permissible.".

For such kind of advertising campaigns the poorly endured lesson is actually individual lesson typically as well as society especially..

\section{FALSE AND DECEPTIVE ADVERTISEMENTS}

An ad is called misleading when it misguides folks, changes the truth and also affects buying practices. Depending On to U.S. Federal Trade Payment Act, 1914, an unfair method of competition in or affecting commerce, and also unethical or deceitful shows or even techniques in or influencing business, are actually illegal. An act or even method is unfair where it:

a. results in or even most likely to create substantial personal injury to consumers,

b. can easily certainly not be reasonably stayed clear of through consumers, and also

c. is actually not over-shadowed through countervailing advantages to buyers or to competition.

\section{NEGATIV EEFFECTS OF MISLEADING MARKETING}

It may be appealing to trick in your promotions certainly not only to make sure that you could possibly entice new clients however also to ensure that they might acquire your products and register for your solutions. Nonetheless, commonly, this technique misbehaves for the future of your provider, as well as it might probably hinder your organisation' effectiveness. Firms whose only objective is to acquire as a lot of revenues as achievable, often tend to utilize ads that might hide some expenses, omit necessary truths, or even use deceptive images, in a bid to obtain consumers to get a service or product. This type of advertising and marketing isn't beneficial, and it will definitely deny customers of the correct information they need to make good, educated decisions. The harmful effects of such marketing impact various gamers in business planet, and are not handy at all.

\section{The Effects of False Advertisements on the Buyer:}

The impacts of underhanded marketing on buyers is actually probably the most awful facet about this kind of advertising. The consumer winds up creating unknowing choices. If you don't tell your clients the reality or paint a picture for all of them with your advertisement that outshines or opposes the reality concerning your services or product, after that they are going to produce inadequate selections concerning those services and products.

\section{The Impacts of False Advertisements on your business:}

An additional result of confusing promotions is actually that of the impacts on the business on its own. When a company generates a misleading statement, then commonly, that service does not see that the advertising will end up as a harm.

\section{What is misleading advertising?}

Under the Consumer Protection Act 2007, advertising is seen as misleading if it involves false, misleading or deceptive information that is likely to cause the average consumer to act in a way they might otherwise not. Advertising may also be considered misleading if important information that the average consumer needs to make an informed decision is left out. Misleading advertising covers claims made directly to consumers by manufacturers, distributors and retailers, as well as in advertisements, catalogues, websites etc

\section{. Examples of misleading advertising}

- A false claim about the characteristics of the goods or service, e.g.-- a product is a different colour, size or weight to what is advertised.

- The price or way the price is calculated is misrepresented, e.g.-- products are advertised at sale prices, but turn out not to be.

\section{SUBLIMINAL MESSAGES}

Subliminal audio communications are actually information radiated directly to the subconsciousness mind. Considering that they are below the level of mindful recognition you can easily certainly not learn or recognize all of them. Because you may certainly not listen to the communications your conscious mind may not deny the information. The subliminal message is actually certainly not regarded by the aware mind, however it goes straight to the subconscious thoughts.

The classic meaning of the condition subliminal is below the threshold of consciousness. Therefore subliminal audio notifications are sent to the subconscious thoughts. It is actually that element of brain which controls some crucial aspects of our body like temp and also remembrance and likewise is actually the main facilitator to our conscious thoughts. 
Dr James Vicary, has actually administered the widely known experiment using subliminal audio messaging. He flashed the words" I want popcorn" as well as" Drink additional coke" to a motion picture viewers for not greater than one hundred milliseconds. No one observed that message, but the snacks sales increased through $57.9 \%$ as well as for coke this was $18.4 \%$. But no person was mindful about the messages that were shown off.

Using subliminal messages strategy were actually outlawed by the US Authorities in 1974. So highly effective was their power that they helped boost the purchase of popcorn through a whooping $60 \%$. Today, they are shown to individuals via "thoughts" programs like that of Derren Brown. lots of people understood it's power as a personal assistance resource. The common people could now utilize the subconscious thoughts to strengthen any type of facet.

Pair of techniques exist to use the subliminal audio information. One is graphic and other is actually sound. The aesthetic method involves utilizing the subliminal video clips and sound is using the subliminal sounds readily available at audio library.

Basic Strategy to Use Subliminal Messages:

If your budget is conservative, you carry out certainly not must fret. There is actually a technique which is going to cost you practically nothing at all and also at the same time you can make use of subliminal audio messaging to become successful for you. The very first step is actually to prioritize your goals. It could be everything like you might want to quit smoking or improve your speed at understanding. Ensure to compose that target in a simple and beneficial kind like" I am actually a fast student" or "I prepare to stop smoking cigarettes".

\section{REVIEW OF LITERATURE}

\section{0-- 2000 (The Time of Globalisation begins):}

Advertising has been considered as a means of information about brands which Puzzles buyer as well as usually misguides (Littlechild,1982). It was highlighted that ethics in service decision-making depends the Presumption that really good principles is actually excellent company (Abratt as well as Sacks, 1988). When inquired about the reputation of a variety of products being promoted on Television, only 2 items were seen as unwanted by an example of college Students: birth control methods for men and birth controls for women. Feminine Care Products has actually additionally been actually stated in industry articles as having Advertising campaigns that remain in "bad taste", "bothersome" and also "very most detested" (Aaker as well as Bruzzone,1985).

Advertising and marketing has always levelled to unfavorable judgments about immoral practices (Singhapakdi and also Vitell, 1990).

( Barnes and Dotson,1990) covered repulsive tv advertising and marketing and Determined 2 various measurements: offending items and also outrageous completion. The products which were in their list featured condoms, women health Products, women undergarments, as well as male undergarments.( Wilkie,1990) acknowledges that advertising possesses both good and unfavorable parts however They do certainly not apply to all advertisements. He has actually specified the "7 sins" billed By advertising's movie critics.
Use subtle forms of advertising and marketing like subliminal audio as well as psychedelic adds needs to have to Be given significant reliable consideration from an individual welfare viewpoint. A Psychoactive advertisement is actually any sort of emotion-arousing ad that can easily induce a purposeful, distinct team of visitors to feel incredibly restless, to really feel hostile toward Others, or even to experience a reduction of self-worth( Hyman and Tansey,1990). Hyman, Tansey and also Clark( 1990) pinpoint 33 prime subjects for those researchers Who consider to focus their initiatives on marketing ethics. The 7 essential Topics out of this list include: use deception in ads, publicizing to little ones, Tobacco advertising and marketing, liquor ads, adverse political advertising and marketing, Ethnological stereotyping, as well as sexual stereotyping.

\section{Literary works Evaluation-- 2001-- 2010 (message globalisation era):.}

Sexuality and also use sexual magnetism in advertising and marketing is actually a significant area of moral worry. Numerous ads present sex-related allures which contemplate unstable duties of women, Presenting them as passive and also looking for continuous alteration or enhancement As suggested (Cohan,2001). Such information have a tendency to truly upset the anxious gender or even teams, as the Ads would incorrectly influence enthusiasts of such information to disrespect the Brought upon groups (Cohan,2001). Vital interest in the mass media to such very noticeable techniques as deceitful Advertising, bait-and-switch selling approaches, the attack of buyer personal privacy, Deceitful rates, and marketing under the role of market research has actually brought up a Number of reliable problems and also threatens to truly stain the image and also Image of reputable marketing practitioners (Kimmel, 2001).

Such notifications also make degrading good example for women, which often tend to be Mistakenly soaked up by the intended team. Cohan experienced that occasionally commercials Certainly not only demean women however progressively transform the psyche of individuals around Women (Cohan, 2001). Nonetheless it was likewise suggested that advertising and marketing was actually a western principle which Little by little slipped into all portion of the planet and also brought several affects on way of life, Viewpoint and worths of the people (Stearn, 2001).

Advertising and marketing is actually thought about as a source of relevant information for all kinds of industries like Economic condition, social and various other think about the advertising globe (Cohan, 2001). Public policy on sexual advertising and marketing might focus on both supply (i.e., the sex-related Advertising campaigns as well as marketers as well as similar others) and also demand (i.e., the Viewers). Having said that, it is very clear that strong overt sexual beauty in print ads Activates dispute and might not be well-received through customers. Smutty use Sexual allure in adds may mistakenly influence uncultivated impressionable thoughts, And as a result legal policies should remain in place to cut and also prohibit such messages. Otherwise, really good of the society continues to be at risk of debilitation through Outrageous photos as well as horrible exposures. (Kimmel,2001). Advertising and marketing is condemned to tend to ratchet up the quest 
for product gain, leading Customers to feel that joy depends upon attaining a higher component Standard of comfort, and acquiring a growing number of factors (Cohan, 2001).

The use of debatable pictures has succeeded or even an amount of Organizations in the past (Phau and also Prendergast, 2001). This is actually specifically Vital when the main reason for debate is based on the attributes of the item. Studies have discovered that products like cigarettes, liquor, condoms, women Birth controls, as well as feminine hygiene items, were actually perceived as debatable Products that could possibly upset when being advertised, however featured in their research Sexual connotations, subject also private, stiring up unnecessary fear, cultural Sensitiveness, rough language, prejudiced graphics and nakedness (Phau and Prendergast,2001).

\section{Literary works Testimonial-- 2011 onwards (Existing Scenario ).}

The direction in which TVCs are relocating today, has actually created substantial social stress to which our team have actually certainly not had the ability to discover ideal options. The situation as on meeting is actually that using these commercials, electrical power has been actually transmitted to business homes that have constantly neglected the social ramifications of their activities. (Singh \& Sandhu, 2011 ).

The complication is essential, as on the manner of the customer review of literary works, it has actually been created that the content of TVCs is wrecking for certainly not only society, yet principles also. Criticisms and worries about TVCs have actually been considerable because their introduction. Although some sizable research study has been actually performed on the bad consequences of TVCs across the planet, the behavioural outcomes and also distortion useful dued to visibility to all of them is actually however an unexplored region. The researchers possess not come upon a lot analysis on this concern in India. This research study is actually, for that reason, well-timed as the community requires to become made aware of the influence of TVCs on the social as well as ethical turnover of the viewers. Via this research study, an attempt has actually been created to assess the social ramifications of unsuitable commercials being actually aired on television in the light of the moral outrage caused by these latest unprofessional patterns (Singh \& Sandhu, 2011).

An unparalleled lot of legal issues are actually dealing with the ad company today. It's not nearly lawsuit, regulations and regulations-- these are greater, better lawful concerns, the kind that will represent real forks in the road as well as critical choice factors for advertising managers. The advertising sector and also the company business is not merely being actually buffeted through change, they are alter brokers. Today, the relevance of advertising and marketing to the economic situation, community and also the introduction of brand-new innovation has never been actually even more crucial (Ron Urbach, 2011).

Have you viewed the advertisement of a semi dressed actress advertising a mango Drink "Aam Sutra". It carries out certainly not take much time to connect it to "Kama Sutra". Of Course, the marketers prefer you to relate to it to ensure that your levels of testosterone Rise and you in some way become crazy for the mango drink. What is the connection Between 'participating in safe' in circumstance of a married couple and also the bottled water? There suffice instances of this particular kind which prove that the company properties have not Been sensitive sufficient to monitor the highest level of ethics while producing Incomes (Shah \& D Souza, 2010). Advertising is a multi crore industry in India and is actually positioned to develop at close to $9 \%$ throughout 2011 . What our company need along this growth is actually a governing body system that sees That the information imparted via the advertising campaign in fact speaks about The service or product to a degree of $90 \%$. The National Commission for Women is actually likewise pressing the Authorities of India to take advertisements and Such media practices under the ambit of a law through proposing changes to The Prohibition of Indecent Portrayal of Women and Kid Act1956. But the all powerful company residences use their lobbying strategies to Dilute such amendments to the magnitude achievable. Let us really hope that common sense Prevails over these corporate residences because a more powerful economic climate may certainly not be actually Built without strong values in company (Gupta Sudhir, 2011). For health and wellness professionals in India, advertising and marketing has typically been seen as a Controversial issue, as well as the notion of using marketing to promote a Specialist strategy is reasonably brand-new. However, advertising and marketing through medical care Specialists in India has improved considerably during recent decade, and also This trend promises to proceed, regardless of a federal government ban and also despite the fact that Many specialists find themselves ill furnished to take care of the characteristics of this particular New as well as altering atmosphere, especially without some type of advertising and marketing Planning (Dable \& Prasanth,2011).

Media principles continued to be a problem for the better aspect of 2011 along with a lot of Challenges manifesting themselves. TheHoot.org has put together a Paperwork on some major issues which developed in an unique document on Ethics in the Indian media (The hoot,2011).

An essay in Muse magazine challenges head on the issues with sexism in Advertising and marketing: There are major social influences coming from this sort of advertising and marketing back On society-- impractical requirements of women's physical bodies and also leading physical body Image complications, sexual and also domestic violence, and bias being enhanced as An appropriate kind of behaviour.we are being actually subconsciously attracted to purchase Products through business that strongly believe that it is all right to use women's bodies in a Sex-related technique to create their brand name cool, hip as well as gorgeous According to (Kaustav Sen Gupta,2011) young people in India form a significant piece as well as are making use of all forms of media To access relevant information regarding most recent gizmos, products, style fads, learning, Lifestyle and so on. Web as well as tv rule this field as well as they access details To the maximum. (Kaustav Sen Gupta, 2011). In a study by (Sujata as well as Bhawna, 2012) it was seen that tv commercials Alone are playing an extremely crucial job in determining the customers particularly who are Teenagers and youthful. Such commercials affect the acquisition choice of These premature thoughts to such a magnitude that they

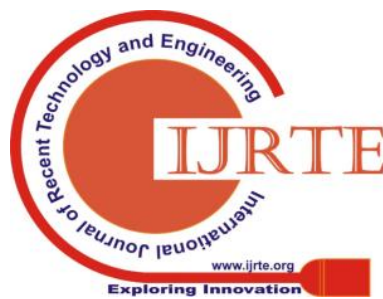


adhere to companies displayed in Commercials with the belief that it would offer very same status, satisfaction as well as Pleasure.

Surrogate Advertising and marketing helps the companies in evading the Authorities and the Rule. A different photo entirely operates backstage where the providers may not Present to be regulation breakers however skillfully blowing wind the laws to their ease. The Innate downside of the application of lawful system, administration, oiling of Palms, faints and allow the providers to accomplish their goals Therefore bypassing the lawful equipments. The liquor field is the main gamer In this particular game. Handful of surrogate promotions are-- Bagpiper Club Soda and also.

Cassettes and also Compact discs, imperial Blue Cassettes and also CDs, Hayward's Soft drink, Royal Obstacle Golf Accessories as well as Bottled Water, Kingfisher Mineral Water, White Mischievousness Holidays, Smirnoff Cassettes and CDs, and so on. The speciality of These products is that they possess the very same trademark name and logo which the Audiences see in booze advertisements. The firms ingeniously flash these Commercials as well as advertise their spirits products. Cigarettes, Paan Masala and also Gutkha creating companies are actually additionally the part of the same bandwagon. Though a Restriction has actually been troubled advertisements supporting cigarette products, this Sector had actually resorted to surrogate advertising a handful of years ago merely. Some Examples in this group are Manikchand Awards, Reddish and also White Courage Awards, Willpowers way of life, Four Square Wild Water Rafting, and so on( Gupta Ruchi, 2011).

In a research it was observed that liquor manufacturers continue to appeal young people and also a Rise in number is observed in the usage among young people. The willful switch to 30 per-cent caused a significantly lower number of liquor advertisements in magazines, According to the center. At the same time, the number of booze commercials Improved, particularly on wire stations. Over half of commercials viewed By youth included some of 12 brand names: Miller Lite, Coors Light, Captain Morgan Rums, Samuel Adams Boston Lager Beer, Miller Genuine Draft Illumination Beer, Dental Crown Royal Scotch, Circle Additional Draft Beer, Disaronno Authentic Amaretto, Smirnoff Vodkas, Miller Chill and Labatt Blue Illumination Beer (Jenna Johnson, 2013).

Indian 'young customers' spending design, mindsets and lifestyles have actually put a Terrific effect on marketing professionals. These young people fill the markets of the Future, while possessing a significant volume of discretionary investing electrical power Today. Young people are actually taking up pivotal placements in the advertising field properly Made up through greater style of living. The way of lives and mindsets have produced an unique improvement in the home entertainment needs when matched up to those of yester opportunities. Youths in India are already having a huge impact on.

\section{STANDARD OF ADVERTISING IN INDIA}

"Advertising is a form of interaction meant to convince a target market (customers, viewers or even audiences) to obtain or even take some action upon products, suggestions, or companies. It features the name of a product and services and how that product or service can profit the customers, to urge a target audience to acquire or even to eat that certain brand." But today, marketing is actually legalized lying. Its own functionality is actually to help make the much worse appear the very best. Marketing is actually the essential to market and advertise commodities and brand names.

The basic idea of an ad is to let the audience evaluate whether the product or even item will certainly serve for a person or otherwise. The advertisement must directly create a favorable and intellectual impact on its audience. Yet the promotions that are on air in today times do not have a solid principle. Several advertising campaigns are actually so deceiving, that eventually the audience thinks about concerning what was the electrical of all the clippings that were presented. Advertising and marketing may be called the scientific research of catching the individual knowledge enough time to receive cash coming from it.

Today the deteriorating requirements of advertising and marketing are actually straight impacting the younger audience creating a bad influence on the little ones. The marketers may not be being able to segregate the time slots as well as decide concerning who is their target audience. It's everything about producing income, whether Ads of birth controls, sanitary napkins and so on, are actually aired on T V channels for small children that first and foremost perform not know what these are indicated for, and second of all, they might get curious to called to what are actually contraceptives and feminine napkins everything about.

It's about the correct advertising at the best place, for the right people, as well as not for simply publicizing an item for huge economical revenue. For instance, the ad of the mango drink Slice, has actually been connected with Aamasutra (drawn from Kamasutra) and also in no other way has any type of correlation to sexuality. A straightforward beverage has actually been actually related to provocative gestures which are certainly not needed to have at all, and particularly because this product is taken in by all age groups, including youngsters which could recognize it in an upside-down.

\section{RESULT}

Based on the literature on ethics and advertising, it is evident that the current research on advertising ethics are focused on issues such as deceptive advertising, subliminal advertising, sex, age and gender manipulation, celebrity endorsement, industry regulation and self-regulation, advertising to children and a few studies on practitioners and advertising stakeholders.

There are relatively few studies focusing on the theological aspect of advertising ethics such as the views on advertising ethics which is evident through the article written by Foley that focuses only on benefits and harms of advertising. The author believes that the area of theological approaches to advertising ethics is a new area to venture into and in need of a thorough study.

\section{CONCLUSION}

Regarding media behaviors are actually concerned majority of all of them view promotion. Television has emerged as the absolute most well-known as well as productive media for checking out advertisements. It is actually complied with through paper and web.

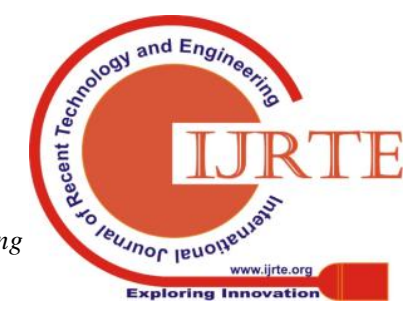


Though the gap is as well wide in between various media the chart suggests expanding recognition of world wide web one of youths. As far as regularity of viewing ads is actually worried bulk of the respondents see ads on regular basis. Many of all of them feel that the effect of adds lasts for a day or less over all of them. Advertising is actually implicated of reassuring materialism and intake, of stereotyping, of affecting our team to acquire items for which our company possess no requirement, of taking advantage of children, and even of controling our behaviour. The objective of this research was to calculate how far the use of deception in adds, sex-related suggestive styles, use women, targeting children, targeting youth, adds of controversial items, health issues, influence younger minds. Especially, the emphasis was to view if transgression of ethical problems had any impact on younger thoughts which are thought about as onslaught.

The explanation behind this research study is to much better comprehend the complex moral concerns in promotions as well as their connection with transforming young people lifestyle. Study has confirmed definite that 'attitude-toward-advertising-in general' is among the important antecedents of 'attitude-toward-the brand name', which, consequently, affects the purchase decision of the vulnerable thoughts. Thus, it is actually advised that marketing professionals need to continue to be in contact with the requirements, perceptions, and opinions of the public for presenting socially reasonable advertisements prior to all of them. Sector needs to reduce the appointments psychological of customers concerning the cultural effects of marketing. Consequently, marketers should integrate unique requirements as well as market values into the planning as well as completion of their ads.

Every day, one stumbles upon lots of images and commercials for Various products. This excessive quantity of media in our everyday resides May not be side edged and also influences all those surrounded through it. It is actually an Expression of the community of which our experts are a part, its mirror-image for all Practical purposes as well as possesses a much connecting with impact on the social, social As well as moral values of its offenders (Ciochetto,2004). The globe is changing Rapidly today and also in its own footprints our core worths are altering as well. The Final two decades therefore globalization have actually observed an unequaled Modification, which has shared itself in the form of reducing Area values. Social worths are actually obtaining deteriorated, ethical market values have Become ragged and the society is dealing with an extraordinary social Cunning. Our culture today is actually tackling brand new worths which are at Loggerheads along with the amount of time assessed and conscientiously allowed principles of Our society, a huge component of the duty for which need to be borne by The television commercials (henceforth TVCs) and likewise the immoral Practices of business as well as corporate homes which fund them. Today, the scope of $t v$ is widespread. Business tv Stations have actually permeated also the furthermost of areas and also the majority of grownups are Left open to hundreds of promotions annually. It is thereby natural for The implications of the offenses of principles by TVCs to become viewed in our Private lives and also on the community as a whole.

Advertising, right now a Days allows business as well as several markets like magazines, the cable television business, papers as well as lots of various other media, non media as well as communication business endure only on the influx of amount of money because of advertising. It is because of this that business houses use all possible tactics to obtain our interest to begin with and cash eventually. Often these attempts include illegal, unclean or even surreptitious methods, making incorrect cases and also reliance on untrue info (Drumwright and also Murphy, 2009). Off overdue, a lot of arguments have been going on about the social problems in marketing and also the devastating effects of improper advertising have been offered the center. The social effects of improper advertising and marketing normally manifest themselves in the form of an unpleasant result on youngster psychological science, human behavior, market value body and also assumption, boost to materialism, rise of consumerism and also corruption, minimized sincerity and personal peace of mind of women as well as degeneration of connections in family members. This study is actually an effort to check out the degree to which these insurance claims hold true.

\section{REFERENCES}

1. Aaker, David A. As Well As Donald E. Bruzzone( 1985 )," Root Causes Of Irritation in Marketing", Publication of Marketing, 49 (Springtime), pp 47-57

2. Abideen, E. P. Sainul and Muraleedharan, K. P.( 1998 )," Moral and Social Issues in Advertising And Marketing." Abhigyan,16( 4 ), October-December, pp 39-41

3. Beltramini, R.F.( 2003 )," Advertising And Marketing Integrity: TheUltimate Figure Of Speech", Journal Of Business Integrities, 48( 3 ), pp 215-216.

4. Beard, F. K. (2008 )," Just How Products as well as Advertising Offend Consumers", Journal of Marketing Research, 48( 1 ), pp 13-21.

5. Burp, G. E. \& Belch, M. A.( 2007 ), Advertising And Marketing as well as Promotion. 1 ed. Boston, McGraw-Hill, New Delhi

6. Bujizen, Moniek and also Patti M. Valkenburg( 2003 )," The unexpected impacts of TELEVISION advertising: a parent- child questionnaire", Communication Investigation, 30( 5 ), 483- 503

7. Austin, M. J. \& Reed, M. L. (1999)," Targeting Youngster Online: World Wide Web Marketing Ethics Issues", Diary of Customer Advertising And Marketing, 16( 6 ), pp 590-602.

8. Pratt, C. B. \& James, E. L.( 1994 )," Marketing Integrities: A Contextual Reaction Based on Timeless Honest Idea", Journal of Organisation Ethics, 13( 6 ), pp 455-468

9. Preston, C. (2004)," Children's Advertising: The Values of Economic Socialisation", International Journal of Individual Studies, 28( 4 ), pp 364-370

10. Priiyanka, Mehra( 2008 )," Youth Marketing-Target: Generation Y." Livemint.com, The Commercial Publication. Feb.http:// information superhighway. Livemint.com/ Youth-Marketing.

11. Rocsearch Ltd( 2006 ), Indian marketing: a review got march 2010 , www.research and also market.com.

12. Rom Urbach (2011 ), 7 Legal Issues That Agencies Should Be Dealing with in 2011, http://adage.com/article/guest-columnists/legal-issues-agencies-Thin king-2011/. 